\title{
AVALIAÇÃO DOS FATORES ENVOLVIDOS NA EXTRAÇÃO DE LIPÍDIOS DA BIOMASSA DA MICROALGA CHLORELLA MINUTÍSSIMA VIA SOLVENTES
}

\author{
S. M. F. E. Zorn ${ }^{1}$, G. A. Pedro ${ }^{1}$, M. S. Amaral ${ }^{1}$, C. C. A. Loures ${ }^{2}$, M. B. Silva ${ }^{1}$ \\ Escola de Engenharia de Lorena - Universidade de São Paulo ${ }^{1}$ \\ Centro Federal de Educação Tecnológica Celso Suckow da Fonseca - Angra dos Reis - RJ ${ }^{2}$ \\ savienne.elerbrock@usp.br \\ Submetido 10/02/2017 - Aceito 08/04/2017 \\ DOI: $10.15628 /$ holos.2017.5655
}

\section{RESUMO}

As microalgas têm se tornado uma fonte promissora de energia renovável; além de fornecerem lipídios, carboidratos, proteínas, vitaminas e pigmentos, dentre outras diversas substâncias de alto valor agregado, contribuem enormemente para a redução do efeito estufa na atmosfera, ao consumirem o dióxido de carbono pela realização de fotossíntese. Os lipídios representam uma importante fonte de matéria prima para a obtenção de biocombustíveis, tal como o biodiesel. Um dos processos de obtenção de lipídios de excelente custo benefício é a extração via solventes, utilizando clorofórmio e metanol. Visando a obtenção do maior rendimento em lipídios por grama de biomassa, foram extraídos lipídios da biomassa da microalga marinha Chlorella minutíssima, empregando um arranjo ortogonal de Taguchi com o estudo simultâneo de quatro fatores que influenciam neste processo: umidade da biomassa, proporção entre os solventes, quantidade total de solventes utilizada e tempo de ultrassom para potencializar a quebra da parede celular, facilitando a liberação destes lipídios. Obteve-se um teor de $20 \%$ em lipídios, pelo emprego de uma biomassa com $64 \%$ de umidade, uma proporção de clorofórmio: metanol: água de 5,7: 3: 1, com um total de $33 \mathrm{~mL}$ de solventes e em apenas 70 minutos de ultrassom. Os lipídios extraídos foram transesterificados em biodiesel etílico via catálise ácida, obtendo-se uma conversão de $94,45 \%$.

PALAVRAS-CHAVE: Extração via solventes, Taguchi, Lipídios, Biomassa úmida, Chlorella minutíssima.

\section{EVALUATION OF FACTORS INVOLVED IN THE LIPID EXTRACTION OF MICROALGA CHLORELLA MINUTÍSSIMA BIOMASS VIA SOLVENTS}

\begin{abstract}
Microalgae have become a promising source of renewable energy; besides providing lipids, carbohydrates, proteins, vitamins and pigments, and other substances with high added value, they contribute greatly to the reduction of greenhouse effect in the atmosphere by consuming carbon dioxide by photosynthesis. Lipids represent an important source of raw material for obtaining biofuels, such as biodiesel. One of the processes for the production of cost-effective lipids is extraction via solvents, using chloroform and methanol. In order to obtain the highest lipid yield per gram of biomass, lipids were extracted from Chlorella
\end{abstract}

minutíssima biomass and a Taguchi orthogonal array was applied, with simultaneous study of four factors that influence at this process: biomass moisture, solvent ratio, total volume of solvents and ultrasound time to potentiate breakdown cell wall, facilitating release of lipids. $20 \%$ lipid content was obtained by employing $64 \%$ wet biomass, a ratio of 5.7 chloroform: 3 methanol: 1 water, $33 \mathrm{~mL}$ total volume and 70 minutes ultrasound time. Lipids were converted to biodiesel by transesterification via acid catalysis, obtaining $94.45 \%$ conversion.

KEYWORDS: Extraction via solvents, Taguchi, Lipids, Wet Biomass, Chlorella minutíssima. 


\section{INTRODUÇÃO}

As fontes de energia de origem fóssil não renovável tais como: carvão mineral, petróleo e seus derivados têm sido continuamente exploradas e utilizadas desde a primeira Revolução Industrial até os dias atuais. De fato, o uso e transformação dessas fontes energéticas contribuíram para enormes avanços tecnológicos e o desenvolvimento industrial de toda a humanidade, contudo, combustíveis de origem fóssil são diretamente ligados ao aumento dos gases poluentes na atmosfera terrestre, que causam o aquecimento global e os desequilíbrios do clima, ao mesmo tempo, afetando a economia global. (Cheah, Show, Chang, Ling, \& Juan, 2015).

A partir da década de 1990, há, no entanto, uma crescente consciência mundial para buscar a diminuição do uso de fontes poluidoras e não renováveis, substituindo-as por energia limpa e renovável.

Nesse cenário surgem as microalgas, fonte promissora de energia renovável, capazes de fornecer diversos produtos e substâncias importantes em diferentes campos tecnológicos e aplicações. No ramo energético, por exemplo, fornecem matéria-prima para gerar biocombustível e apresentam como vantagem, o fato de não concorrerem com fontes de alimento, como a soja (Derner, Ohse, Villela, Carvalho, \& Fett, 2006). As microalgas podem ser cultivadas em áreas abertas ou fechadas, com luz artificial ou natural, não dependendo das condições climáticas para seu crescimento. Adaptam-se a diferentes condições de cultivo, reproduzindo-se e crescendo rapidamente, gerando biomassa cuja colheita pode ser realizada em ciclos semanais, o que é um tempo significativamente menor comparado ao das plantações de grãos (Koller, Muhr, \& Braunegg, 2014; Milano et al., 2016). Além disso, contribuem enormemente para a redução do dióxido de carbono na atmosfera, visto que, para cada tonelada de biomassa microalgal gerada, são consumidos 1,83 toneladas de dióxido de carbono atmosférico (Cheah et al., 2015; Patil \& Honaguntikar, 2014).

Embora o número de espécies de algas seja ainda indeterminado, estima-se que está acima de dez milhões de espécies, a maioria das quais são provavelmente microalgas, de elevada diversidade. Estima-se que existam até um milhão de espécies de microalgas, sendo que atualmente cerca de quarenta e quatro mil espécies já são conhecidas.

As microalgas podem fornecer diversas substâncias úteis e de alto valor agregado: ácidos graxos poli-insaturados, carotenoides, ficolibinas, polissacarídeos, vitaminas, esteróis, antioxidantes e redutores de colesterol (denominados compostos bioativos naturais), os quais podem ser empregados especialmente no desenvolvimento de alimentos funcionais, devido às suas propriedades nutricionais e farmacêuticas e no campo energético fornecem diferentes tipos de biocombustíveis, como metano, hidrogênio, bio-óleo e etanol (Cardoso, Eliza, Vieira, \& Kappes, 2011).

Dentre estas diversas substâncias de interesse, destacam-se os lipídios. Lipídios algais são compostos por glicerol ou bases esterificadas de ácidos graxos saturados ou insaturados (Neofotis et al., 2016).

Dentre todos os ácidos graxos encontrados nas microalgas, alguns das famílias ômega 3 e ômega 6 são de particular interesse (Ferreira, Souza-soares, Alberto, \& Costa, 2013; Mesko \& Jacob-lopes, 2012). No grupo dos lipídios, encontram-se os lipídios neutros como triglicerídeos, 
diglicerídeos, monoglicerídeos, ácidos graxos livres e lipídios polares, como os fosfolipídios, entre outros (Kwietniewska, Tys, Krzeminska, \& Koziel, 2012). O conteúdo lipídico das células algais pode variar entre $1 \%$ e $70 \%$, podendo alcançar teores ainda mais elevados, conforme as condições de cultivo empregadas e a espécie escolhida (Neofotis et al., 2016).

Dentre as muitas espécies conhecidas, as microalgas marinhas são de especial interesse para a obtenção de lipídios a partir de sua biomassa, visto que, adaptam-se com facilidade em condições similares ao ambiente marinho e, sob condições adequadas de cultivo, reproduzem-se com facilidade e rapidez, produzindo conteúdos significativos de lipídios, inclusive podem ser cultivadas em águas residuais de estações de tratamento (He et al., 2016; Kwietniewska et al., 2012).

Seja para a produção de biodiesel ou para a obtenção de outras substâncias de valor agregado, como ômega 3 e ômega 6, a utilização de métodos confiáveis para uma extração adequada e reprodutível, de baixo custo, e em condições seguras, não agressivas ao meio ambiente, objetivando a produção de lipídios em ampla escala, é de extrema importância, visto que este processo fornece a matéria prima básica de interesse para outros produtos acabados: os lipídios (Du, Schuur, Kersten, \& Brilman, 2015).

Assim, este trabalho dedicou-se ao estudo de quatro variáveis que interferem no processo de extração dos lipídios da biomassa microalgal, a partir de uma condição de cultivo padronizada, em específico: a umidade da biomassa, volume total de solventes (clorofórmio, metanol e água), proporção entre os solventes empregados e tempo de ultrassom.

\section{REVISÃO BIBLIOGRÁFICA}

De acordo com KWIETNIEWSKA et al. (2012), algas são os mais simples organismos autotróficos difundidos na Terra. Seu número é ainda indeterminado, mas estima-se em até 10 milhões, a maioria das quais são provavelmente microalgas, isto é, algas unicelulares. Além disso, sua diversidade é imensa, formando um grupo polifético de espécies autotróficas eucarióticas.

Conforme NEOFOTIS et al. (2016), pode-se chegar até um milhão de espécies de microalgas, sendo que atualmente cerca de quarenta e quatro mil espécies já são conhecidas.

Com referência à biomassa de algas, algumas vantagens consideráveis sobre as demais matérias primas tradicionais (as oleaginosas) são: alta produtividade: normalmente $10-100$ vezes maior do que as culturas terrestres, captura altamente eficiente de dióxido de carbono, elevado teor de lipídios ou de amido, que podem ser usados na produção de biodiesel ou bioetanol, respectivamente (Neofotis et al., 2016).

As microalgas podem ser cultivadas em áreas abertas ou fechadas, com luz artificial ou natural, em água salgada ou doce, águas salobras ou residuais, não dependendo das condições climáticas para seu crescimento, inclusive, utilizando terreno de terras não aráveis. Adaptam-se a diferentes condições de cultivo, reproduzindo-se e crescendo rapidamente, gerando biomassa cuja colheita pode ser realizada em ciclos semanais, ao longo de todo o ano, o que é um tempo expressivamente menor, comparado ao das plantações de grãos.

Sob condições ótimas de cultivo, as microalgas multiplicam-se rapidamente, porém não acumulam tanto substâncias de armazenamento, tais como carboidratos e lipídios. Por outro lado, sob condições ambientais desfavoráveis, ou seja, sob stress, causado principalmente pela 
deficiência de nutrientes, principalmente nitrogênio e fósforo, ocorre o acúmulo de tais substâncias (Kwietniewska et al., 2012; Mesko \& Jacob-lopes, 2012). O teor de lipídios de microalgas varia consideravelmente de uma espécie para outra e pode abranger, em termos de biomassa seca, de 5 a 77 \% ou mais (Chisti, 2007; Mata, Martins, \& Caetano, 2010). Níveis lipídicos de 20 a $50 \%$ são bastante comuns de serem obtidos.

Há diversos métodos que podem ser empregados para obtenção de lipídios, a partir de sua biomassa, como por exemplo, tecnologia supercrítica, micro-ondas, ultrassom, água subcrítica, e misturas de diferentes solventes, contudo, algumas dessas tecnologias embora possam apresentar bons resultados, requerem elevado investimento em equipamentos e em sua manutenção, bem como, demandam elevado consumo de energia (Du et al., 2015; Reddy et al., 2014).

Dentre os diferentes métodos existentes, os métodos de extração por solventes destacam-se devido à sua praticidade, baixo custo dos reagentes empregados e recuperação dos solventes para reutilização. Um destes métodos, publicado originalmente por Bligh \& Dyer em 1959, apesar de empregado para tecidos de origem animal, tem-se mostrado promissor quando aplicado à biomassa microalgal, especialmente por permitir trabalhar com elevados teores de umidade nesta biomassa (Bligh \& Dyer, 1959; Chatsungnoen \& Chisti, 2016).

Visto que a biomassa recém colhida após filtração contém ainda cerca de 60 a $85 \%$ de água, a extração nessas condições é um fator positivo e relevante de economia de energia e de tempo de processo (Arora, Patel, Pruthi, \& Pruthi, 2016; Chatsungnoen \& Chisti, 2016).

O método original de Bligh \& Dyer emprega solventes de baixo custo (metanol e clorofórmio), de baixa toxicidade, e que podem ser facilmente recuperados e reutilizados (Bligh \& Dyer, 1959).

Diversos estudos demonstram que a utilização de algumas técnicas de pré tratamento atuam como coadjuvantes no processo de extração, potencializando-o. Umas dessas técnicas é a utilização do ultrassom, que pode elevar em mais de $50 \%$ o teor de lipídios extraídos da biomassa (Dos Santos, Moreira, Kunigami, Aranda, \& Teixeira, 2015; Garoma \& Janda, 2016).

Neste contexto, o presente trabalho estudou simultaneamente quatro fatores no processo de extração dos lipídios da biomassa microalgal: o teor de umidade presente na biomassa, a proporção entre os solventes utilizados, a quantidade de solventes empregada e o tempo de ultrassom, sob condições controladas, visando alcançar a melhor condição ou condições que resultem na obtenção do maior teor de lipídios extraídos, com o menor consumo de solventes possível e menor tempo de processamento.

A microalga marinha Chlorella minutíssima foi escolhida, em virtude de ser uma espécie que se adapta a diferentes condições de cultivo em larga escala, rica em ácidos graxos poliinsaturados, especialmente o EPA (Ácido Ecosapentaenoico). Os lipídios totais extraídos são uma fonte promissora de matéria prima para o biodiesel, bem como para diversas outras aplicações, tais como fármacos e alimentos funcionais.

Para a eficácia na condução do estudo simultâneo destas quatro variáveis em três diferentes níveis, bem como, a análise e proposição dos melhores ajustes, foi utilizada como ferramenta estatística o arranjo ortogonal L9 de Taguchi. O estudo simultâneo destes quatro fatores, combinados em um arranjo ortogonal de Taguchi, permite distinguir quais deles realmente interferem no processo de extração, objetivando o maior teor de lipídios totais 
extraídos, no menor tempo de processamento possível, com uma redução no consumo de solventes; ao utilizar a biomassa com elevados índices de umidade, objetiva-se a economia em tempo de processo e redução no consumo de energia.

\section{METODOLOGIA}

\subsection{Cultivo da microalga}

Foi utilizada neste trabalho a microalga marinha Chlorella minutíssima, cuja cepa foi gentilmente doada pelo Departamento de Oceanografia Biológica do Instituto Oceanográfico da USP, São Paulo. Esta espécie tem suas condições de cultivo bem desenvolvidas e ajustadas e foi determinada de acordo com C. C. Loures et al., (2015) empregando o meio modificado de Guillard f/2.

\subsection{Fotobioreatores, acompanhamento do crescimento e colheita da microalga}

O cultivo ocorreu em três fotobioreatores de colunas de volume útil de 44 litros, sob iluminação constante de 24 horas, sob luz fluorescente e aeração constante, sem injeção de dióxido de carbono; o período de inoculação até a colheita compreendeu cerca de sete dias.

Durante este período, foram realizadas análises de absorbância via espectrofotômetro uvvisível para acompanhamento do crescimento das microalgas, findo o qual, a biomassa foi colhida e floculada, utilizando-se solução de sulfato de alumínio $1 \mathrm{~N}$, filtrada a vácuo, embalada em papel alumínio, identificada e armazenada a $-20^{\circ} \mathrm{C}$, para posterior utilização.

\subsection{Preparação da biomassa}

A biomassa microalgal congelada foi retirada do freezer, permanecendo em repouso à temperatura ambiente por um período de 12 horas. Após este período, foi distribuída cuidadosamente sobre um vidro de relógio com o auxílio de uma espátula, e levada a secar em estufa a uma temperatura controlada entre 55 a $60{ }^{\circ} \mathrm{C}$, por um período de 24 horas. Após secagem até peso constante, a biomassa foi triturada utilizando-se gral e pistilo de porcelana até obter uma consistência homogênea; em seguida foi acondicionada em frasco hermeticamente fechado e identificado.

\subsection{Quantidade de amostra e hidratação controlada}

Para cada uma das extrações realizadas, foi pesado $1 \mathrm{~g}$ da biomassa seca em frasco erlenmeyer de $125 \mathrm{~mL}$. Em seguida, foi adicionada a respectiva quantidade de água destilada, com pipetador automático, perfazendo a porcentagem de umidade de acordo com o experimento a ser realizado, determinado aleatoriamente. O período de hidratação foi de 30 minutos em ultrassom.

\subsection{Planejamento de experimentos e escolha dos fatores}

Os fatores e seus respectivos níveis foram aplicados conforme a Tabela 1.

\begin{tabular}{c|c|c|c}
\hline Fatores/Níveis & 1 & 2 & 3 \\
\hline A - Umidade da biomassa (\%) & 64 & 72 & 80 \\
B - Proporção de solventes & $2: 2: 1$ & $2: 2,5: 1$ & $5,7: 3: 1$ \\
C - Volume total solventes (mL) & 10 & 20 & 33 \\
D - Tempo ultrassom (min) & 50 & 70 & 90 \\
\hline
\end{tabular}

Tabela 1: Fatores e níveis da matriz experimental. 
Os reagentes empregados, clorofórmio e metanol, são de grau analítico. Utilizou-se água destilada. Todos os experimentos foram realizados em triplicata.

Os níveis dos fatores foram escolhidos, levando-se em consideração os mais significativos, em termos de resultados obtidos nos processos de extração de lipídios por solventes.

\subsection{Níveis dos fatores}

Para os níveis da umidade da biomassa, Bligh \& Dyer (1959) enfatizam a importância de se trabalhar com um tecido contendo $80 \%$ de umidade e Neofotis et al. (2016) obtiveram excelentes resultados com uma biomassa microalgal com $72 \%$ de umidade; decidiu-se avaliar os efeitos em uma escala decrescente de umidade, daí o menor nível da matriz experimental em $64 \%$.

Para os níveis de proporção de solventes, de acordo com Bligh \& Dyer (1959), a proporção do sistema ternário clorofórmio: metanol :água foi de 2:2:1, enquanto que $\mathrm{F}$ Smedes \& Thomasen (1996); Foppe Smedes \& Askland (1999) estudaram um incremento na quantidade de metanol para melhores resultados de extração, relacionado ao rompimento das paredes das células (2:2,5:1) e Chatsungnoen \& Chisti (2016) obtiveram ótimos resultados com um nível mais elevado de clorofórmio e metanol (5,7:3:1).

Para os níveis de volume de solventes, verificou-se na literatura uma variabilidade quanto aos volumes totais empregados; vários destes encontram-se dentro dos níveis especificados na Tabela 1.

Para os níveis de tempo de ultrassom, os tempos de ultrassom empregados podem variar de 20 minutos até acima de 4 horas, de onde foram testados os três diferentes níveis estabelecidos neste trabalho (Adam, Abert-Vian, Peltier, \& Chemat, 2012; Dos Santos et al., 2015; Garoma \& Janda, 2016).

\subsection{Extração dos lipídios}

Os experimentos com a aplicação simultânea dos fatores e seus respectivos níveis obedeceram criteriosamente ao arranjo ortogonal L9 de Taguchi, conforme a Tabela 2.

\begin{tabular}{ccccc}
\hline Experimento $\mathrm{N}^{\circ}$. & Fator $\mathrm{A}$ & Fator $\mathrm{B}$ & Fator $\mathrm{C}$ & Fator $\mathrm{D}$ \\
\hline 1 & 1 & 1 & 1 & 1 \\
2 & 1 & 2 & 2 & 2 \\
3 & 1 & 3 & 3 & 3 \\
4 & 2 & 1 & 2 & 3 \\
5 & 2 & 2 & 3 & 1 \\
6 & 2 & 3 & 1 & 2 \\
7 & 3 & 1 & 3 & 2 \\
8 & 3 & 2 & 1 & 3 \\
9 & 3 & 3 & 2 & 1 \\
\hline
\end{tabular}

Tabela 2: Arranjo ortogonal L9 de Taguchi.

\subsection{Processo de extração}

O processo de extração consistiu de três etapas distintas:

Etapa 1: Adição de clorofórmio e metanol ao erlenmeyer contendo a amostra hidratada, agitação manual por 2 minutos e agitação via banho de ultrassom à temperatura ambiente, pelo tempo especificado conforme o experimento em andamento; 
Etapa 2: Retirada do erlenmeyer do banho de ultrassom, adição de clorofórmio, agitação manual por mais 2 minutos, e em seguida nova agitação via banho de ultrassom à temperatura ambiente, pelo tempo especificado conforme o experimento em andamento.

Etapa 3: Retirada do erlenmeyer do banho, adição de água destilada conforme especificado para o experimento em andamento e agitação manual por mais 2 minutos. Após a etapa 3, foi realizada a filtração do conteúdo do erlenmeyer, com papel de filtro de $12,5 \mathrm{~cm}$ de diâmetro, filtragem média. A biomassa ficou retida no papel de filtro e o filtrado foi cuidadosamente coletado e diretamente transferido para um funil de separação de vidro de 125 $\mathrm{mL}$. Este filtrado permaneceu em repouso, até a total separação de fases. A fase inferior foi cuidadosamente coletada em frascos de pesagem que foram previamente limpos, secos em estufa e pesados em balança analítica, sendo a massa do frasco vazio registrada.

Os frascos contendo a fase inferior do filtrado foram identificados, levados para evaporação do solvente em estufa a $55-60{ }^{\circ} \mathrm{C}$ por um período de 24 horas. Finalizado este tempo, os frascos foram retirados da estufa e deixados em dessecador por 15 minutos, para resfriamento à temperatura ambiente. Os frascos foram novamente pesados e sua massa final registrada.

\subsection{Cálculo dos lipídios em porcentagem}

A quantidade de lipídios obtida em gramas em cada experimento foi calculada em porcentagem, em relação a $1 \mathrm{~g}$ de biomassa seca, conforme a Equação (1):

$$
\% \text { Lipídios }=(\mathrm{m} 2-\mathrm{m} 1) \times 100
$$

Onde $\mathrm{m} 2$ refere-se à massa do frasco contendo lipídios e $\mathrm{m} 1$ refere-se à massa do frasco vazio, em gramas.

3.10 Transesterificação dos lipídios da microalga

O processo de síntese de ésteres de etila (biodiesel) foi realizado em balão de fundo redondo, acoplado a um condensador de refluxo, em banho de água aquecido e com agitação magnética. O meio reacional foi composto de lipídios e etanol na razão molar 1:30, catalisado por ácido sulfúrico $(10 \% \mathrm{~m} / \mathrm{m})$, à temperatura de $80^{\circ} \mathrm{C}$, durante 5 horas.

A análise em Ressonância Magnética Nuclear de Hidrogênio (RMN1H) é utilizada para contabilizar o número de hidrogênios presentes no composto da amostra, sendo, então, possível identificar a conversão dos lipídios em ésteres etílicos nesta amostra, observando os picos característicos de éster de etila. A indicação da presença de éster de etila em um espectro de $\mathrm{RMN}^{1} \mathrm{H}$ é o quarteto (quatro picos) entre 4,05 e 4,35 ppm, característico do grupo etóxido, formado durante a reação de transesterificação.

\section{RESULTADOS E DISCUSSÃO}

Ao todo quatro etapas principais compreenderam o trabalho experimental, a saber:

- $\quad$ Cultivo da microalga (meio f2 de Guillard) sem adição de fontes de carbono;

- $\quad$ Colheita da biomassa, composta por floculação e filtração;

- $\quad$ Preparação da biomassa (secagem e moagem);

- $\quad$ Extrações (etapa principal, onde é inserido o Planejamento de Taguchi); 
O material lipídico foi convertido em ésteres de etila por transesterificação para demonstrar a qualidade dos lipídios extraídos.

A Figura 1 ilustra esquematicamente as principais etapas que compuseram o presente trabalho.

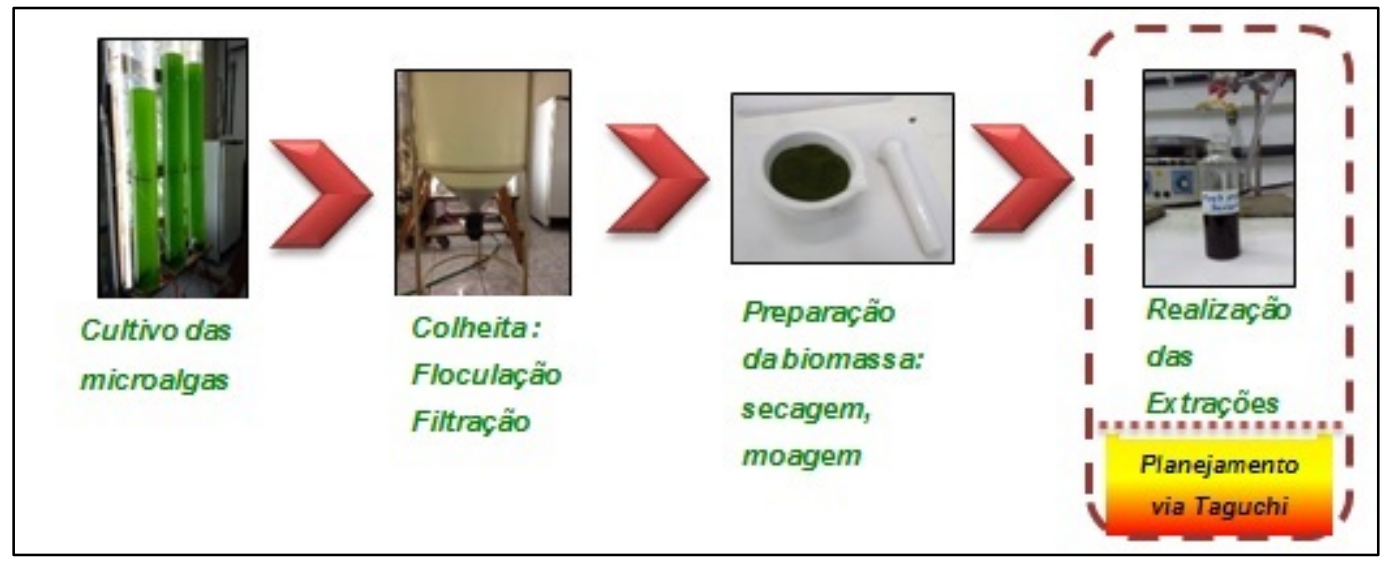

Figura 1: Etapas do trabalho experimental.

\subsection{Análise estatística}

Os experimentos foram realizados para avaliar a influência dos fatores: umidade da biomassa, proporção de solventes, quantidade total de solventes e tempo total de ultrassom, sobre o teor de lipídios extraídos da biomassa da microalga marinha Chlorella minutíssima, visando encontrar o melhor ajuste que proporcionasse o maior rendimento em lipídios, no menor tempo possível e com menor consumo de solventes. Os efeitos dos quatro fatores aplicados simultaneamente, em três diferentes níveis, foram investigados pela aplicação do método de Taguchi. Os resultados encontrados, em triplicata, são apresentados na Tabela 3:

\begin{tabular}{cccc}
\hline & \multicolumn{3}{c}{ Lipídios (\%) } \\
Exp N $^{\circ}$ & Ensaio 1 & Ensaio 2 & Ensaio 3 \\
\hline 1 & 6,4 & 6,3 & 6,6 \\
2 & 15,3 & 15,7 & 15,1 \\
3 & 19,8 & 19,7 & 20 \\
4 & 9,1 & 9,5 & 9,4 \\
5 & 15,4 & 15,6 & 15,3 \\
6 & 7,3 & 7,4 & 7,6 \\
7 & 12,9 & 12,7 & 12,9 \\
8 & 4,2 & 4,6 & 4,4 \\
9 & 9,8 & 10 & 9,6 \\
\hline
\end{tabular}

Tabela 3: Resultados obtidos nas extrações.

De acordo com os resultados apresentados na Tabela 3, o Experimento 3, cujos fatores de entrada são: umidade da biomassa de $64 \%$, proporção de solventes de 5,7:3:1, volume total de solventes de $33 \mathrm{~mL}$ e tempo de ultrassom total de 90 minutos apresentou-se como o ajuste que 
forneceu o maior rendimento em lipídios extraídos da biomassa microalgal; esses resultados foram trabalhados através do software estatístico Minitab, para verificação da influência do efeito destes fatores na confirmação da condição do experimento 3 ou a proposição de novos ajustes experimentais.

4.2 Efeito dos fatores para obtenção do maior teor em lipídios

O efeito dos fatores: A (Umidade da Biomassa), B (Proporção de solventes), C (Volume total de solventes) e $D$ (Tempo de Ultrassom) foi verificado através do software estatístico Minitab, os resultados constam da Figura 2 e Figura 3.

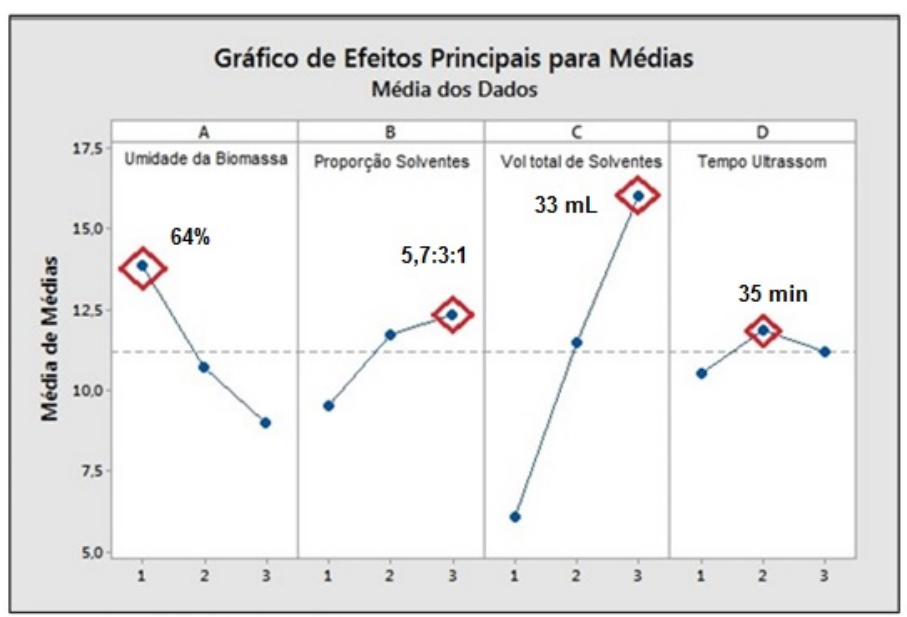

Figura 2: Efeitos principais das médias.

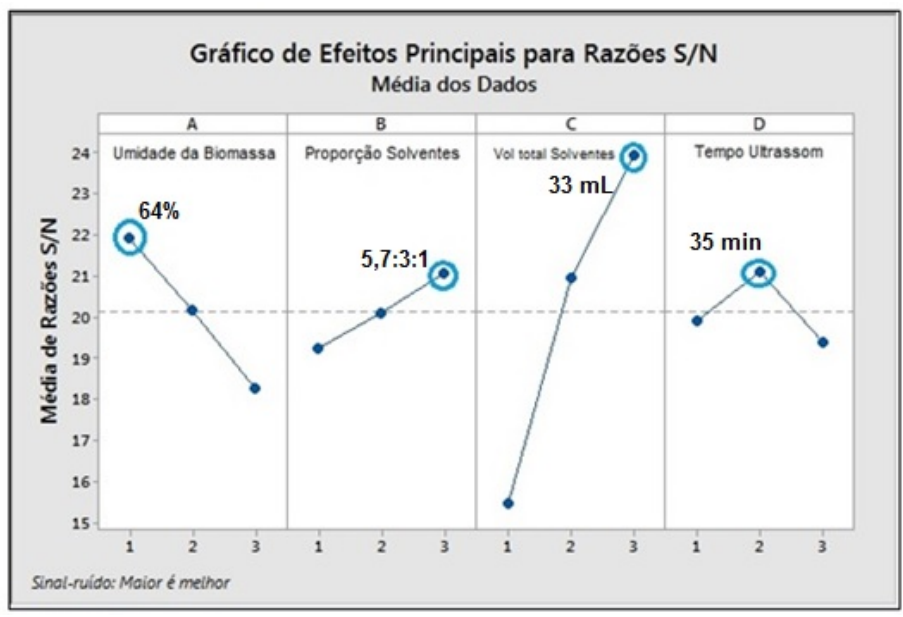

Figura 3: Efeitos principais para Razões S/N.

Verificou-se, através dos gráficos acima, que os maiores teores em lipídios foram obtidos utilizando-se a umidade da biomassa, a proporção de solventes e o volume total de solventes respectivamente nos níveis 1, 3 e 3 que significam, respectivamente, $64 \%$ de umidade na biomassa, proporção de solventes 5,7:3:1 e volume total de solventes de $33 \mathrm{~mL}$. Para o fator $\mathrm{D}$, que significa o tempo de ultrassom empregado, o nível 2 refere-se a um tempo de 35 minutos de ultrassom por etapa, totalizando 70 minutos. Contudo, propõe-se investir no emprego de um tempo de ultrassom de 25 minutos por etapa (total de 50 minutos), visto que, na análise desta 
variável, não se nota diferença significativa entre os níveis 1 e 2, o que representa economia no tempo do processo de extração e consequentemente no consumo de energia.

As condições dos experimentos 2 e 5 também merecem ser consideradas, visto que o teor de lipídios obtido nestes experimentos foi em média de 15,4\%, embora inferior ao resultado do experimento 3, a condição 5 trabalha com uma biomassa com $72 \%$ de umidade, enquanto que a condição do experimento 2 utiliza um volume total de solventes de $20 \mathrm{~mL}$.

É importante ressaltar que a produtividade lipídica varia grandemente, dependendo principalmente: da estirpe escolhida e das condições de cultivo; estas condições incluem o meio, constituído pelos diferentes nutrientes, ausência ou emprego de fontes de carbono, como injeção de gás Dióxido de Carbono ou de outras fontes (sais orgânicos e ou carboidratos), iluminação, aeração, temperatura ambiente e salinidade, bem como tipos de reatores empregados. Tais condições podem influenciar positivamente no aumento do conteúdo lipídico, conforme adequadamente ajustadas e aplicadas.

No presente trabalho, não houve como objetivo empregar condições visando o aumento do conteúdo lipídico nas células, e sim, a partir de condições e meio de cultivo controlados, avaliar simultaneamente a influência de quatro diferentes fatores no processo de extração do material lipídico.

Diversos autores investigaram a influência de fatores sobre a produção de lipídios a partir da biomassa microalgal, contudo evidenciou-se em seus trabalhos que estes fatores foram estudados em separado e não de forma simultânea, como no presente trabalho. A biomassa da microalga Nannochloropsis salina, cultivada em meio estéreo BG11, com água do mar artificial e injeção constante de gás $\mathrm{CO}_{2}(5 \% \mathrm{vol} / \mathrm{vol})$ contendo $72 \%$ de umidade, foi utilizada por Chatsungnoen \& Chisti, (2016), que, empregando os solventes clorofórmio, metanol e água, e agitação de $760 \mathrm{rpm}$ durante 4 horas, obtiveram 39\% de lipídios totais. As microalgas Nannochloropsis oculata e Dunaliella salina foram cultivadas e, da biomassa úmida, com cerca de $80 \%$ de água, Dejoye Tanzi; Abert Vian; Chemat, (2013) obtiveram respectivamente $23,7 \%$ e 4,0\% de lipídios totais pelo método original de Bligh e Dyer.

Balasubramanian; Yen Doan; Obbard (2013) estudaram os fatores que afetam a extração lipídica das células da microalga marinha Nannochloropsis $s p$ e constataram que os solventes clorofórmio e metanol foram os melhores para a obtenção de um maior rendimento em lipídios totais (cerca de $22 \%$ ), ao passo que a umidade da biomassa acima de $5 \%$ influenciou fortemente na eficiência do processo de extração, contudo, com um sistema de solventes adequado, esta influência é controlada. Converti et al. (2009) extraíram aproximadamente 24,0\% de lipídios totais da biomassa da microalga Nannochloropsis oculata, utilizando a mistura de clorofórmio e metanol assistida por ultrassom.

Diversos métodos de extração foram avaliados por Dos Santos et al. (2015), que avaliaram diferentes solventes, com e sem uso de ultrassom, utilizando como substrato a biomassa da Chlorella vulgaris. Os solventes avaliados foram etanol, hexano, clorofórmio:metanol (1:2), clorofórmio:metanol (2:1); o melhor resultado foi obtido por clorofórmio:metanol (2:1) assistido por ultrassom (igual a 19\% de lipídios totais).

Dada a ampla variabilidade de fatores que podem influenciar na extração de lipídios totais da biomassa microalgal, o presente trabalho apresenta-se promissor por permitir uma extração simples e reprodutível, com baixo consumo de solventes e em pouco tempo; este estudo comprova ainda que se pode trabalhar com a biomassa com elevado teor de umidade (entre 64 e $72 \%$ ) com economia de energia e de tempo. 


\subsection{Conversão dos lipídios extraídos em ésteres de etila (Biodiesel)}

Os lipídios extraídos de acordo com as condições do experimento 3 foram convertidos em ésteres de etila, por transesterificação via catálise ácida. Utilizando-se a análise em Ressonância Magnética Nuclear de Hidrogênio $\left(\mathrm{RMN}^{1} \mathrm{H}\right)$, foi possível estimar o percentual de conversão dos lipídios em ésteres, através da relação das áreas dos picos relativos aos ésteres e das áreas relativas aos lipídios, conforme determina Garcia (2006).

De acordo com o espectro $\mathrm{RMN}^{1} \mathrm{H}$ demonstrado na Figura 4, a presença de ésteres etílicos na amostra é confirmada pela formação do quarteto (quatro picos em sequencia) no intervalo de 4,05 a 4,35 ppm. A conversão obtida, calculada conforme Garcia (2006), foi de 94,45\%, considerada uma alta conversão pela literatura.

Assim, a conversão obtida pela reação de transesterificação evidencia que $94,45 \%$ dos lipídios, extraídos pela melhor condição experimental, são esterificáveis. Isso permite afirmar que as condições de extração propostas neste trabalho são viáveis para fornecer a matéria-prima para a produção de biodiesel.

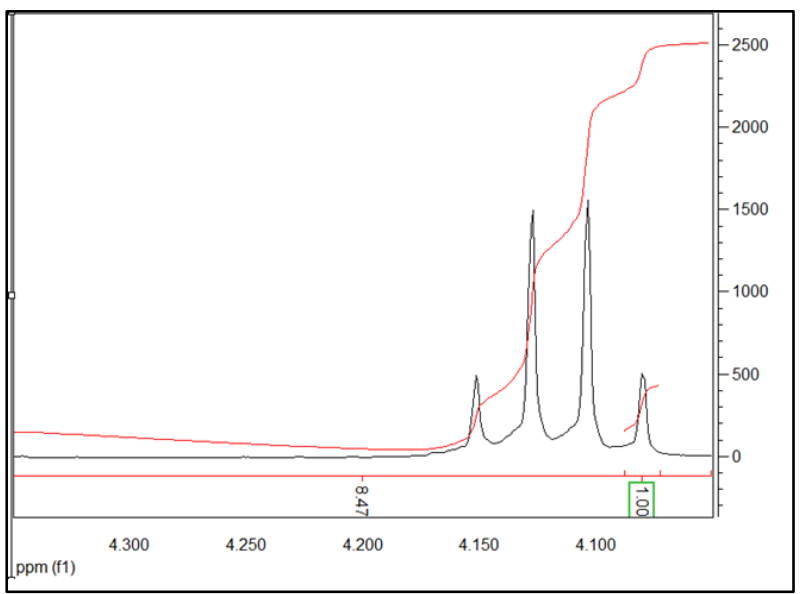

Figura 4. Espectro RMN-H de ésteres de etila convertido a partir dos lipídios obtidos por extração via solventes (Experimento 3).

\section{CONCLUSÕES}

Através da avaliação simultânea de quatro fatores: umidade de biomassa, proporção de solventes, volume total de solventes e tempo de ultrassom, verificou-se que os lipídios podem ser extraídos da biomassa da Chlorella minutíssima contendo ao menos $64 \%$ de umidade, na proporção de solventes de 5,7: 3: 1 respectivamente para clorofórmio: metanol: água e com um volume total de solventes de $33 \mathrm{~mL}$ para $1 \mathrm{~g}$ de biomassa microalgal. Essas condições proporcionaram um teor de lipídios de $20 \%$, cujo processo pode ainda ser otimizado aplicando-se um tempo de ultrassom no nível mais baixo, de 25 minutos por etapa. Outras condições experimentais que utilizaram biomassa com $72 \%$ de umidade e um volume total de solventes de apenas $20 \mathrm{~mL}$ podem ser melhor investigadas, tendo-se, assim, ao menos três opções de extração com economia de energia, de solventes e do tempo de processo. A posterior conversão dos lipídios extraídos em ésteres de etila demonstrou a eficácia do processo de extração. $O$ presente trabalho confirmou que a umidade da biomassa, a proporção de solventes e o volume 
total são os fatores mais influentes no processo de extração de lipídios totais, o que foi possível pela aplicação do arranjo ortogonal de Taguchi.

\section{AGRADECIMENTOS}

Agradecemos à equipe do Laboratório de Engenharia de Microalgas, ao Prof. Dr. Messias Borges Silva pela orientação na condução deste trabalho, à Prof. . Dra' Daniela Pellegrini Guimarães pelo apoio e suprimentos e à Prof. ${ }^{\text {a }}$ Dra' Jayne Barboza pela orientação e apoio quanto às análises de espectrofotometria via RMN-H. À CAPES pelo apoio financeiro.

\section{REFERÊNCIAS}

Adam, F., Abert-Vian, M., Peltier, G., \& Chemat, F. (2012). "Solvent-free" ultrasound-assisted extraction of lipids from fresh microalgae cells: A green, clean and scalable process. Bioresource Technology, 114, 457-465. http://doi.org/10.1016/j.biortech.2012.02.096

Arora, N., Patel, A., Pruthi, P. A., \& Pruthi, V. (2016). Synergistic dynamics of nitrogen and phosphorous influences lipid productivity in Chlorella minutissima for biodiesel production. Bioresource Technology, 285530. http://doi.org/10.1016/j.biortech.2016.02.112

Balasubramanian, R. K., Yen Doan, T. T., \& Obbard, J. P. (2013). Factors affecting cellular lipid extraction from marine microalgae. Chemical Engineering Journal, 215-216, 929-936. http://doi.org/10.1016/j.cej.2012.11.063

Bligh, E. G., \& Dyer, W. J. (1959). Canadian Journal of Biochemistry and Physiology. Canadian Journal of Biochemistry and Physiology, 37(8), 389-395. http://doi.org/dx.doi.org/10,1139/cjm2014-0700

Cardoso, A. S., Eliza, G., Vieira, G., \& Kappes, A. (2011). O uso de microalgas para a obtenção de biocombustíveis. In Revista Brasileira de Biociência (Vol. 9, pp. 542-549).

Chatsungnoen, T., \& Chisti, Y. (2016). Optimization of oil extraction from Nannochloropsis salina biomass paste. Algal Research, 15, 100-109. http://doi.org/10.1016/j.algal.2016.02.015

Cheah, W. Y., Show, P. L., Chang, J.-S., Ling, T. C., \& Juan, J. C. (2015). Biosequestration of atmospheric $\mathrm{CO} 2$ and flue gas-containing $\mathrm{CO} 2$ by microalgae. Bioresource Technology, 184, 190-201. http://doi.org/10.1016/j.biortech.2014.11.026

Chisti, Y. (2007). Biodiesel from microalgae. Biotechnology Advances, 25(3), 294-306. http://doi.org/10.1016/j.tibtech.2007.12.002

Converti, A., Casazza, A. A., Ortiz, E. Y., Perego, P., \& Del Borghi, M. (2009). Effect of temperature and nitrogen concentration on the growth and lipid content of Nannochloropsis oculata and Chlorella vulgaris for biodiesel production. Chemical Engineering and Processing: Process Intensification, 48(6), 1146-1151. http://doi.org/10.1016/j.cep.2009.03.006

Derner, R. B., Ohse, S., Villela, M., Carvalho, S. M. De, \& Fett, R. (2006). Microalgas, produtos e aplicações. Ciência Rural, 36(6), 1959-1967. http://doi.org/10.1590/S010384782006000600050

Dos Santos, R. R., Moreira, D. M., Kunigami, C. N., Aranda, D. A. G., \& Teixeira, C. M. L. L. (2015). Comparison between several methods of total lipid extraction from Chlorella vulgaris biomass. Ultrasonics Sonochemistry, 22, 95-99. http://doi.org/10.1016/j.ultsonch.2014.05.015

Du, Y., Schuur, B., Kersten, S. R. A., \& Brilman, D. W. F. (2015). Opportunities for switchable solvents for lipid extraction from wet algal biomass: An energy evaluation. Algal Research, 


\section{1, 271-283. http://doi.org/10.1016/j.algal.2015.07.004}

Ferreira, S. P., Souza-soares, L. De, Alberto, J., \& Costa, V. (2013). Revisão : microalgas : uma fonte alternativa na obtenção de ácidos gordos essenciais Review: microalgae: an alternative source to obtain essential fatty acids. SCAP Sociedade de Ciências Agrárias de Portugal, 36(3), 275-287.

Garcia, C. M. (2006). Transesterificação de óleos vegetais. Universidade Estadual de ampinas, Instituto de Química.

Garoma, T., \& Janda, D. (2016). Investigation of the effects of microalgal cell concentration and electroporation, microwave and ultrasonication on lipid extraction efficiency. Renewable Energy, 86, 117-123. http://doi.org/10.1016/j.renene.2015.08.009

He, Y., Chen, L., Zhou, Y., Chen, H., Zhou, X., Cai, F., ... Guo, Z. (2016). Analysis and model delineation of marine microalgae growth and lipid accumulation in flat-plate photobioreactor. Biochemical Engineering Journal, 111, 108-116. http://doi.org/10.1016/j.bej.2016.03.014

Koller, M., Muhr, A., \& Braunegg, G. (2014). Microalgae as versatile cellular factories for valued products. Algal Research, 6(PA), 52-63. http://doi.org/10.1016/j.algal.2014.09.002

Kwietniewska, E., Tys, J., Krzeminska, I., \& Koziel, W. (2012). Microalgae - Cultivation and Application of Biomass as a Source of Energy: A Review. Instytut Agrofizyki. http://doi.org/10.1017/CB09781107415324.004

Loures, C. C., Amaral, M. de S., Laiate, J., Da Rós, P. C. M., De Castro, H. F., G, M. M. A., \& Siva, M. B. (2015). Assembling of a bubble-column photobioreactor for the cultivation of a marine microalgae Chlorella minutissima. In IV Solabiaa Latin American Congress. Florianópolis, Brazil.

Mata, T. M., Martins, A. A., \& Caetano, N. S. (2010). Microalgae for biodiesel production and other applications: A review. Renewable and Sustainable Energy Reviews, 14(1), 217-232. http://doi.org/10.1016/j.rser.2009.07.020

Mesko, F., \& Jacob-lopes, E. (2012). Biodiesel derived from microalgae: Advances and perspectives. In Química Nova (Vol. 35, pp. 2013-2018).

Milano, J., Ong, H. C., Masjuki, H. H., Chong, W. T., Lam, M. K., Loh, P. K., \& Vellayan, V. (2016). Microalgae biofuels as an alternative to fossil fuel for power generation. Renewable and Sustainable Energy Reviews, 58, 180-197. http://doi.org/10.1016/j.rser.2015.12.150

Neofotis, P., Huang, A., Sury, K., Chang, W., Joseph, F., Gabr, A., ... Polle, J. E. W. (2016). Characterization and classification of highly productive microalgae strains discovered for biofuel and bioproduct generation. Algal Research, 15, 164-178. http://doi.org/10.1016/j.algal.2016.01.007

Patil, J. A., \& Honaguntikar, P. (2014). An Overview on Developments in Biodiesel Production from Algae. International Journal of Science and Research (IJSR), 3(12), 102-106.

Reddy, H. K., Muppaneni, T., Sun, Y., Li, Y., Ponnusamy, S., Patil, P. D., ... Deng, S. (2014). Subcritical water extraction of lipids from wet algae for biodiesel production. Fuel, 133, 7381. http://doi.org/10.1016/j.fuel.2014.04.081

Smedes, F., \& Askland, T. K. (1999). Revisiting the development of the Bligh and Dyer total lipid determination method. Marine Pollution Bulletin, 38(3), 193-201. http://doi.org/10.1016/S0025-326X(98)00170-2

Smedes, F., \& Thomasen, T. K. (1996). Evaluation of the Blight and Dyer lipid determination method. Marine Pollution Bulletin, 32(1), 681-688. 
